\title{
Enterobacter aerogenes and Enterobacter cloacae; versatile bacterial pathogens confronting antibiotic treatment
}

\author{
Anne Davin-Regli* and Jean-Marie Pagès \\ Transporteurs Membranaires, Chimiorésistance et Drug Design, Facultés de Médecine et Pharmacie, UMR-MD1, IRBA - \\ Aix-Marseille Université, Marseille, France
}

\section{OPEN ACCESS}

Edited by:

Marta Martins,

University College Dublin, Ireland

Reviewed by:

Etinosa Igbinosa,

University of Benin, Nigeria Alessandra Polissi,

Università degli Studi

di Milano-Bicocca, Italy

*Correspondence:

Anne Davin-Regli,

Transporteurs Membranaires, Chimiorésistance et Drug Design, Facultés de Médecine et Pharmacie, UMR-MD1, IRBA - Aix-Marseille

Université, 27 Boulevard Jean Moulin, 13385 Marseille Cedex 05, France anne-veronique.regli@univ-amu.fr

Specialty section:

This article was submitted to Antimicrobials, Resistance and Chemotherapy,

a section of the journal

Frontiers in Microbiology

Received: 11 March 2015

Accepted: 16 April 2015

Published: 18 May 2015

Citation:

Davin-Regli A and Pagès J-M (2015)

Enterobacter aerogenes and Enterobacter cloacae; versatile bacterial pathogens confronting antibiotic treatment.

Front. Microbiol. 6:392. doi: 10.3389/fmicb.2015.00392
Enterobacter aerogenes and E. cloacae have been reported as important opportunistic and multiresistant bacterial pathogens for humans during the last three decades in hospital wards. These Gram-negative bacteria have been largely described during several outbreaks of hospital-acquired infections in Europe and particularly in France. The dissemination of Enterobacter sp. is associated with the presence of redundant regulatory cascades that efficiently control the membrane permeability ensuring the bacterial protection and the expression of detoxifying enzymes involved in antibiotic degradation/inactivation. In addition, these bacterial species are able to acquire numerous genetic mobile elements that strongly contribute to antibiotic resistance. Moreover, this particular fitness help them to colonize several environments and hosts and rapidly and efficiently adapt their metabolism and physiology to external conditions and environmental stresses. Enterobacter is a versatile bacterium able to promptly respond to the antibiotic treatment in the colonized patient. The balance of the prevalence, $E$. aerogenes versus $E$. cloacae, in the reported hospital infections during the last period, questions about the horizontal transmission of mobile elements containing antibiotic resistance genes, e.g., the efficacy of the exchange of resistance genes Klebsiella pneumoniae to Enterobacter sp. It is also important to mention the possible role of antibiotic use in the treatment of bacterial infectious diseases in this $E$. aerogenes/E. cloacae evolution.

Keywords: Enterobacter aerogenes, Enterobacter cloacae, membrane and transporters, regulation, resistance mechanisms

\section{Introduction}

Enterobacter is a genus of a common Gram-negative, facultative anaerobic, rod-shaped, nonspore-forming bacteria belonging to the family Enterobacteriaceae. Two of its well-known species, Enterobacter aerogenes and E. cloacae have taken on clinical significance as opportunistic bacteria and have emerged as nosocomial pathogens from intensive care patients pathogenic, especially to those who are on mechanical ventilation (Mezzatesta et al., 2012).

Enterobacter aerogenes was originally named Aerobacter aerogenes, and was later included in the genus Enterobacter in 1960. In 1971, this species was proposed to be renamed Klebsiella mobilis due to its motility conferred by peritrichous flagella and its genetic relatedness to Klebsiella 
genus. It is interesting to note that phenotypic dissimilarities between E. aerogenes and the genus Klebsiella include not only the motility but also the presence of ornithine decarboxylase (ODC) activity and the lack of urease activity in E. aerogenes (Farmer et al., 1985). However, recently, the whole genome sequencing of a multidrug-resistant (MDR) clinical isolate, (including colistin) suggested a possible reclassification of the species in the genus Klebsiella, under the name $K$. aeromobilis (Diene et al., 2013). E. aerogenes particular phenotype can be attributed to the horizontal acquisition of additional genes from other Enterobacteriaceae species and mobile elements that rapidly integrated and translated as easily as its own ancestral heritage (Diene et al., 2013). For example, the flagellar genes and its assembly system have been acquired in bloc from the Serratia genus. Plasmid conjugation is a chimera of transposons and genetic elements (conjugation, integration) of various bacterial origins. E. aerogenes also contains eight rRNA operons and 87 tRNA associated with the ability to translate imported genes that use different codons, improving its ability to use its integrated foreign genes. E. aerogenes has been involved in significant European outbreak between 1993 and 2003 and is considered as the paradigm of opportunistic bacteria.

Species of the E. cloacae complex are widely encountered in nature, but they are also pathogens: $E$. cloacae and $E$. hormaechei are most frequently isolated from human clinical specimens. Thus, E. cloacae is among the most common Enterobacter sp. causing only nosocomial infections in the last decade and a lot has been published on the antibioticresistance features of these microorganisms. Despite the relevance of E. cloacae as a nosocomial pathogen, the pathogenic mechanisms and factors contributing in the disease associated with the E. cloacae complex are not understood yet; this could be due to the scarcity and the dispersion of information available. Its ability to form biofilms and to secrete various cytotoxins (enterotoxins, hemolysins, pore-forming toxins) are important for its pathogenicity (Mezzatesta et al., 2012). Some genotypes and species, have previously exhibited some associations with clinical specimens, in particular urines and sputum, when clonal outbreaks with members of the E. cloacae complex were rare (Izdebski et al., 2014). Interestingly, due to the diffusion of most frequent extended spectrum $\beta$-lactamases (ESBL) and carbapenemases in this species, E. cloacae has now become the third broad spectrum Enterobacteriaceae species involved in nosocomial infections after Escherichia coli and K. pneumoniae (Potron et al., 2013; Jarlier and INVS, 2014).

\section{Epidemiology and Infections}

Enterobacter aerogenes is isolated as human clinical specimens from respiratory, urinary, blood, or gastrointestinal tract (Langley et al., 2001). Epidemiology of this species has been particular in Europe: it has regularly been involved in nosocomial infections outbreaks since 1993, particularly in the Western Europe (Georghiou et al., 1995; Grattard et al., 1995; Allerberger et al., 1996; Arpin et al., 1996; Davin-Regli et al., 1996; De Gheldre et al., 1997; Jalaluddin et al., 1998). Until, 2003, E. aerogenes was considered as an important emerging MDR pathogen, particularly in ICUs (Bosi et al., 1999; Chevalier et al., 2008; Figure 1). The situation in 1990s in Europe pointed to the dispersion of an epidemic clone and, since then, it has been extensively detected in European hospitals and health care facilities. The event fitted in with the international spread of the ESBL TEM-24 $\left(b l a_{\mathrm{TEM}-24}\right)$ harbored by an epidemic plasmid (Bosi et al., 1999). The prevalence of Enterobacter sp. infections in clinical wards has also increased due to the introduction of extended-spectrum cephalosporins and carbapenems in the antibiotic therapy (Arpin et al., 1996; Anastay et al., 2013). The consequence of this antibiotherapy is the emergence of "pan-drug E. aerogenes isolates" resistant to last-line antibiotics such as carbapenems and also to colistin, for which no therapeutic option was available (Chevalier et al., 1999; Thiolas et al., 2005; Diene et al., 2013). Interestingly, the role of efflux mechanism in E. aerogenes resistance has been studied within an 8 years of period. This study indicated a noticeable increase of the prevalence of an efflux mechanism, susceptible to pump inhibitor, in clinical isolates collected during this period (Chevalier et al., 2008). After the emergence of ESBL in $E$. aerogenes and the characterisation of porin mutations in clinical isolates, this role of efflux mechanism highlights a new step in the adaptative evolution in E. aerogenes (Charrel et al., 1996; Malléa et al., 1998; Gayet et al., 2003).

Since 2010, E. aerogenes in France is the fifth highest Enterobacteriaceae and the seventh highest Gram-negative Bacillus responsible for notorious nosocomial infections (Carbonne et al., 2013; Figure 2). Despite its intrinsic resistance to ampicillin and constant expression of ESBL that is associated with other resistance mechanisms contributing to MDR phenotype, its prevalence has significantly dropped (reduction factor of 20) in France (Anastay et al., 2013; Jarlier and INVS, 2014). Its position was displaced in the context of hospital acquired infections, because of the dramatic rise of the E. coli pandemic clone O25:H4-ST131 along with K. pneumoniae and E. cloacae, ESBL, and/or carbapenemase producing strains. Although, E.

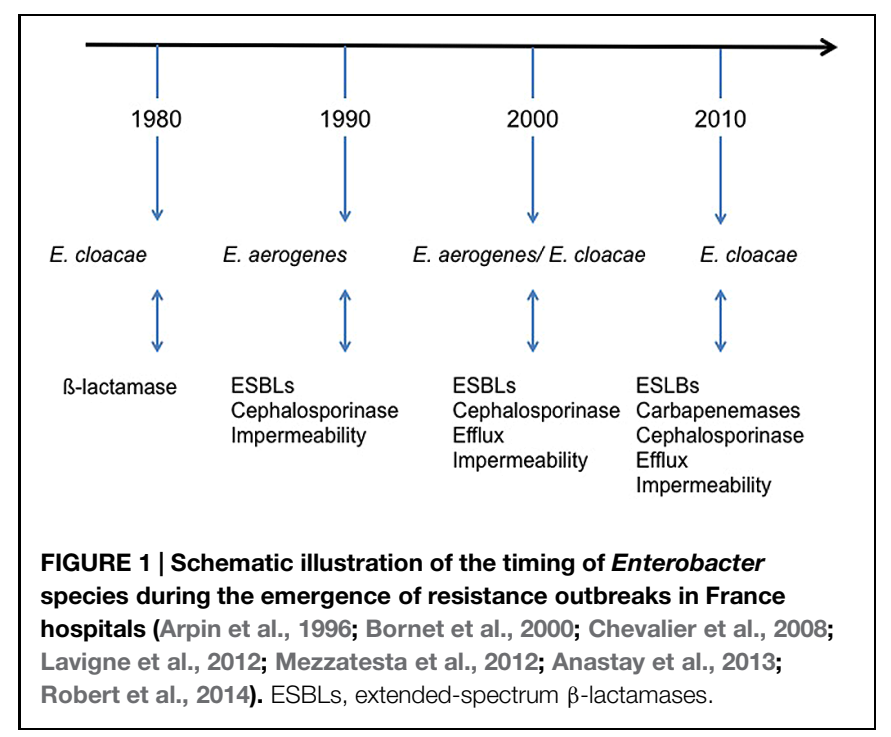




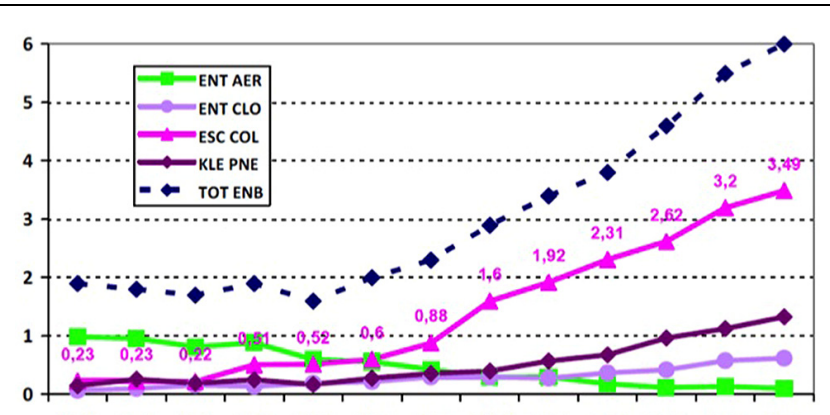

$\begin{array}{lllllllllllll}2001 & 2002 & 2003 & 2004 & 2005 & 2006 & 2007 & 2008 & 2009 & 2010 & 2011 & 2012 & 2013\end{array}$

FIGURE 2 | Distribution of the main species of Enterobacteriaceae-ESBL ( $n$ for 10,000 patient days): evolution 2002-2013 from the French national coordination of MDRB surveillance (Carbonne et al., 2013; Jarlier and INVS, 2014). ENT AER, Enterobacter aerogenes; ENT CLO, E. cloacae; ESC COL, E. coli; KLE PNE, Klebsiella pneumoniae; TOT ENB, Total Enterobacteriaceae; ESBLs, extended-spectrum $\beta$-lactamases.

aerogenes causes septic shock more readily in patients thus leading to a higher mortality rate (Song et al., 2010; Lavigne et al., 2012), E. cloacae is now the most frequently observed clinical isolate among Enterobacter sp. It can be associated with the dissemination of actual epidemic plasmids bearing most prevalent resistant genes and expressing new $\beta$-lactamases or carbapenemases (Figure 2).

Enterobacter cloacae is ubiquitous in terrestrial and aquatic environments (water, sewage, soil, and food). The species occurs as commensal microflora in the intestinal tracts of humans and animals and is also pathogens in plants and insects. This diversity of habitats is mirrored by the genetic variety of E. cloacae (Mezzatesta et al., 2012). Recently, MLST and PFGE epidemiological methods data revealed world circulation of several epidemic clonal complexes (Izdebski et al., 2014).

It is also a well-known nosocomial pathogen contributing to bacteremia, endocarditis, septic arthritis, osteomyelitis, and skin/soft tissue infections, and lower respiratory tract- urinary tract and intra-abdominal infections (Fata et al., 1996). E. cloacae tends to contaminate various medical, intravenous, and other hospital devices (Dugleux et al., 1991). Nosocomial outbreaks have also been associated with the colonization of certain surgical equipment and operative cleaning solutions (Wang et al., 2000). Since a decade, E. cloacae has been repeatedly reported as a nosocomial pathogen in neonatal units and several outbreaks of infection have been reported (Fernandez-Baca et al., 2001; Pestourie et al., 2014). Today, variability among strains are less frequent and outbreaks due to clonal E. cloacae hyper-producing AmpC $\beta$-lactamase and ESBL carrier isolates are described from neonate specimens, adults urines/feces samples or from environmental samples (Pestourie et al., 2014).

Enterobacter cloacae has an intrinsic resistance to ampicillin, amoxicillin, first-generation cephalosporins, and cefoxitin owing to the production of constitutive AmpC $\beta$-lactamase. It exhibits a high frequency of enzymatic resistance to broadspectrum cephalosporins. Resistance of Enterobacter sp. to third-generation cephalosporins is most typically caused by overproduction of AmpC $\beta$-lactamases, and thus treatment with third-generation cephalosporins may select for AmpCoverproducing mutants. AmpC overproduction is due to the derepression of a chromosomal gene or by the acquisition of a transferable $a m p C$ gene from plasmids or other mobile elements. The AmpC plasmid-mediated resistance is distinguished from chromosomal enzyme production because they are not inducible. However they represent a problem due to its increasing prevalence among clinical isolates. The enzyme confers a resistance to third-generation cephalosporins and ureido- and carboxy-penicillins and is not inhibited by common inhibitors of $\beta$-lactamases. Fourth-generation cephalosporins retain reasonable activity against derepressed strains, but if strains are also ESBL producers, they become resistant to this antibiotic class. The prevalence of ESBL and CTX-M producers represented approximatively $5 \%$ of the isolates in the recent studies and ESBLs are most often plasmid-mediated. These characteristics, associated with the frequent endogenous intestinal carriage of E. cloacae, may result in abnormally high levels in the bowels of hospitalized patients, especially those who have received cephalosporins (Potron et al., 2013).

\section{Enzymatic Barrier and Antibiotic Resistance}

The production of $\beta$-lactamases is the prominent mechanism responsible for $\beta$-lactam resistance in most of these species. $E$. aerogenes strains have a broad ability to develop antibiotics resistance mechanisms (Miro et al., 1995). They naturally express a chromosomal AmpC $\beta$-lactamase type cephalosporinase at low level (group $1 \mathrm{Bush}$ ) that induces resistance to first-generation cephalosporins (Freney et al., 1988). Chromosomal acquired $\beta$-lactams resistance mechanisms induce the overproduction of chromosomal AmpC cephalosporinase: this results from an induction during a third-generation cephalosporin treatment or by a mutation in the AmpR repressor, and generates a resistance to almost all $\beta$-lactams (Preston et al., 2000). Moreover, it has been described that E. aerogenes strains harboring cephalosporinase AmpC gene, integrated the gene of chromosomal origin (blaCMY-10) on a large plasmid $(130 \mathrm{~kb})$, contributing to a systematic gene transmission even in the absence of antibiotic pressure (Lee et al., 2003).

In 1993 appeared the first cases of nosocomial infections caused by strains with resistance to common $\beta$-lactam antibiotics due to ESBL (Pitout et al., 1998). The ESBL TEM- 24 associated to E. aerogenes clonal dissemination in France was constantly reported (Neuwirth et al., 1996; Bosi et al., 1999; Bertrand et al., 2003). Other ESBLs of TEM type or CTX-M type (ex CTX-M-2) are often identified but TEM-24 remains associated with preferential conjugative plasmid of this species (Arpin et al., 2002; Dumarche et al., 2002; Biendo et al., 2008; Kanamori et al., 2012). Due to the well-described modification of porins expression and recent dissemination of plasmid bearing carbapenemases, a number of imipenem-resistant clinical strains have come up (Miro et al., 1995; Bornet et al., 2000; Biendo 
et al., 2008; Lavigne et al., 2012). Carbapenemases of NDM and VIM types are now, as anticipated, reported in E. aerogenes in India and those for the serine protease group as KPC or class $\mathrm{D} \beta$-lactamases possessing carbapenemase properties as OXA-48 types are described in Europe/Asia (Khajuria et al., 2014; Torres et al., 2014).

Similarly to E. aerogenes, E. cloacae is also naturally resistant to ampicillin, amoxicillin-clavulanic acid, cephalothin, and cefoxitin by low production of the natural inducible cephalosporinase of Bush group 1 (class $\mathrm{C}$ ). They are capable of overproducing AmpC $\beta$-lactamases by blocking the repression of a chromosomal gene or by the acquisition of a transferable $a m p C$ gene on plasmids conferring the resistance to third-generation cephalosporins (Nauciel et al., 1985; Zaher and Cimolai, 1997). Cefepime alone can keep its activity (Sanders and Sanders, 1997). Clinical AmpC resistance represents $50 \%$ of the isolates and frequently co- exists with the expression of ESBL. In 1989, appeared the first nosocomial isolate cases bearing plasmidic ESBL causing also resistance to third generation cephalosporins except cefamycins (De Champs et al., 1989). Together, these enzymes are responsible for a global resistance to all $\beta$-lactams except carbapenems (Pitout et al., 1997). In the last decade, E. cloacae has emerged as the third most common Enterobacteriaceae resistant to third generation cephalosporins with enteric E. coli and $K$. pneumoniae (Jarlier and INVS, 2014). Imipenem remains the most effective molecule for treating E. cloacae infections. Since then, various ESBL of TEM, SHV, and CTX -M types have been characterized in E. cloacae including resistant TEM inhibitors or IRT (for inhibitor-resistant TEM; Arpin et al., 2002; Szabo et al., 2005; Galas et al., 2008). However, among ESBL producers, some sub-clones are now identified, associated with CTX-M-3 and 15 production, when other TEM or SHV (SHV-12 for example) types are also associated with epidemic-episodesinvolved isolates. Diffusion of E. cloacae producing CTX-M-15 ESBL is the consequence of the wide dissemination of identical or related plasmids harboring the CTX-M-15 gene firstly identified in the epidemic E. coli clone, and the CTX-M $\beta$-lactamases are now the most prevalent ESBL globally (Hammami et al., 2012).

In recent years, clinical isolates resistant by producing carbapenemases have been identified (Nordmann et al., 1993; Galani et al., 2005). In 2010, CDC first reported carriage of NDM-1 in E. cloacae from patients who received medical care in India. Especially in Asia, strains harboring metallo- $\beta$-lactamases as IMP -type enzymes, NDM, GIM, VIM, and serine carbapenemase type KPC have been described (Huang et al., 2012; Dai et al., 2013; Hamprecht et al., 2013; Jaskulski et al., 2013). The OXA48 type serine carbapenemase is the most prevalent because its gene is located on a plasmid, associated to the bla-CTXM-15 gene coding ESBL, thus explaining its spread and the associated resistance (Potron et al., 2013; Torres et al., 2014). A hike in the imipenem resistance rate in E. cloacae, from 0.4 to $8 \%$, has been observed (Lee et al., 2005; Poirel et al., 2007; Robert et al., 2014). An epidemic study concerning E. cloacae blood stream infections indicated a $25 \%$ production of metallo- $\beta$-lactamase in corresponding strains (Khajuria et al., 2014). Thus, the decreased susceptibility to carbapenems in hospital acquired E. cloacae isolates might arise via stepwise accumulations of MDR determinants in different clones. Today, E. cloacae is the second Enterobacteriaceae carrying carbapenemase and strains co-expressing two carbapenemases has been reported (Izdebski et al., 2014).

Regarding the aminoglycosides, the major mechanism of resistance of the Enterobacteriaceae is due to aminoglycosidemodifying enzymes that are often plasmid-encoded, but it may also be associated with transposable elements. These enzymes are assigned to three groups: acetyltransferases (acetylation of an amino group/AAC), phosphotransferases (phosphorylation of a hydroxyl group/APH), and adenylyltransferases (adenylylation of a hydroxyl group/AAD or ANT). Plasmid exchanges and disseminations of transposons facilitate the rapid acquisition of resistance phenotypes (Mezzatesta et al., 2012).

The resistant strain varies from 0 to $51 \%$ resistance for gentamicin, and 0 to $34 \%$ for amikacin (Sanders and Sanders, 1997). In 2013, an important epidemiological study confirmed that the aminoglycoside-modifying genes involved in aminoglycosideclinical resistance were $a a c(3)-I I a, a a c\left(6^{\prime}\right)-I b$, and ant $\left(2^{\prime \prime}\right)-I a$, genes that confer resistance to tobramycin, gentamicin, and amikacin (Miró et al., 2013). Strains have frequently more than one enzyme (Miró et al., 2013). This enzymatic type resistance is associated in $77 \%$ of clinical isolates in China to other plasmid genes (armA, rmtB; Huang et al., 2012). Among these, the aminoglycoside $\mathrm{AAC}\left(6^{\prime}\right)$-Ib is the most common cause of amikacin resistance among members of the Enterobacteriaceae family. In a previous study, it was observed that over $40 \%$ of the E. cloacae isolates had the aac $\left(6^{\prime}\right)$-Ib gene, although many of the isolates with this gene were susceptible to amikacin and gentamicin, which were the most active of all tested drugs (Kim et al., 2009).

The enzymatic resistance to fluoroquinolones has been recently described and attributed to a two-point mutation allele of $a a c\left(6^{\prime}\right)-I b$ [named $a a c\left(6^{\prime}\right)-I b-c r$ ], the aminoglycosides resistance enzymatic determinant, which acetylates ciprofloxacin and norfloxacin (Huang et al., 2012). A systematic molecular survey reporting prevalence and characteristics of $a a c\left(6^{\prime}\right)-I b-c r$ in Korea, characterized a high prevalence of the mechanism $(23 \%)$ in $E$. cloacae (Huang et al., 2012). Dissemination of this new enzymatic resistance mechanism occurs since the $a a c\left(6^{\prime}\right)-I b-c r$ is highly associated with bla $a_{\mathrm{OXA}-1}$, ISCR1, and class 1 integron. This supports the previous finding where $a a c\left(6^{\prime}\right)-I b-c r$ was located upstream of bla $a_{\mathrm{OXA}-30}$ (synonymously called bla $a_{\mathrm{OXA}-1}$ ) in complex class 1 integron, In37 containing ISCR1 (Quiroga et al., 2007). A genetic linkage between $a a c\left(6^{\prime}\right)-I b-c r$ and $b l a_{\mathrm{CTX}-\mathrm{M}-15}$ has been demonstrated (Huang et al., 2012).

\section{Membrane Barrier and Antibiotic Resistance}

\section{Porin and Membrane Permeability}

Carbapenems are the most powerful agents for the treatment of serious nosocomial infections caused by MDR Enterobacteriaceae. Due to the imipenem use, it was rapidly reported a decreased penetration of $\beta$-lactams due to a change 
in the expression of porins in E. aerogenes isolates. Charrel et al. (1996) showed that MDR strains of E. aerogenes exhibited a characteristic phenotype associated with an altered expression of porins and then successive studies comforted description of more frequent MDR strains in treated patients by $\beta$-lactams (Bornet et al., 2000; Fernandez-Cuenca et al., 2006). This mechanism of resistance is reversible upon discontinuation of treatment (Bornet et al., 2000) and progressive during treatment. Among intermediate strains which are susceptible to imipenem but resistant to ertapenem, there is a loss of porin Omp35 but the expression of porin Omp36 is preserved. When treatment with imipenem continues, the disappearance of two porins and resistance to all carbapenems is noted (Lavigne et al., 2013). Recently, a novel mechanism of resistance has been observed in a clinical strain where the antibiotic cannot be efficiently translocated through a mutated porin (see Mutation and Antibiotic Resistance). Additionally, imipenem and carbapenemase KPC type have been described as responsible for resistance to carbapenems associated to decrease in membrane permeability (Jaskulski et al., 2013). The conductance and selectivity of these porins, Omp35, and Omp36, correspond to the properties obtained with OmpC and OmpF of E. coli (Bornet et al., 2004; James et al., 2009). Moreover, several studies have further described a decrease in production of these porins in resistant isolates (Bornet et al., 2000; Yigit et al., 2002; Gayet et al., 2003; Doumith et al., 2009; Tran et al., 2009). Two major outer membrane porins have been identified in E. cloacae and studied by liposome swelling assays (Lee et al., 1992). These porins are involved in the carbapenem susceptibility (Raimondi et al., 1991; Lee et al., 1992) and exhibit important cross antigenicity with the E. aerogenes porins in specific key parts, e.g., eyelet region, membrane insertions, subunit connections (Malléa et al., 1995). In addition, their respective involvement in $\beta$-lactam and fluoroquinolone uptake has been reported (Chevalier et al., 2000; James et al., 2009).

Interestingly, the expression of porin in Enterobacteriaceae is rapidly and notably altered by various stress compounds present in the external medium (Dupont et al., 2007). During the first hours of incubation in the presence of salicylate, novobiocin, norfloxacin a significant increase of OmpX is observed and this overexpression negatively controls the synthesis of porins (Dupont et al., 2007).

\section{Efflux and Membrane Permeability}

Furthermore, an efflux mechanism that is involved in the expelling of molecules from the bacteria such as fluoroquinolones, tetracycline, and chloramphenicol is active in Enterobacter sp. (Malléa et al., 1998). This mechanism is highly efficient since the AcrAB-TolC efflux pump can eject about $80-90 \%$ of the norfloxacin during the first 10-15 min (Malléa et al., 1998). Interestingly, this process is energy-dependent and requires the membrane energy (proton motive force) as extensively described (for a recent review see Nikaido and Pagès, 2012). Approximately $40 \%$ of MDR clinical strains have an active efflux (Chevalier et al., 2008). The EefABC and AcrAB-TolC efflux genes of $E$. aerogenes have been described and their involvement in antibiotic exportation has been studied (Pradel and Pagès,
2002; Masi et al., 2005, 2006; Martins et al., 2010). Several studies on E. cloacae have also reported the presence of efflux pumps belonging to RND and MATE families (Pérez et al., 2007; He et al., 2011). In addition, the AcrAB-TolC and OqxAB genes have been characterized in E. cloacae clinical resistant isolates (Pérez et al., 2007, 2012; Veleba et al., 2013). In E. aerogenes and E. cloacae, the sequence similarities and biological activity are particularly high in AcrAB-TolC (Pradel and Pagès, 2002; Pérez et al., 2007). Moreover, various chemicals such as salicylate, chloramphenicol, and imipenem are also able to trigger the genetic cascade controlling the expression of Enterobacter AcrAB-TolC pump (Davin-Regli et al., 2008). The regulation seems to be associated with the internal concentration of chemicals that plays a key role during the switch on of the cascade that provides the efflux expression (Valade et al., 2013).

MarA acts as a key regulator for the expression of porin genes and tolC in Enterobacteriaceae (Levy, 2002; Piddock, 2006; Alekshun and Levy, 2007; Davin-Regli et al., 2008). SoxS is another key transcriptional regulator that is positively controlled by oxidative stress and can trigger the MarA expression (Masi and Pagès, 2013). Some Enterobacteriaceae sp., such as Enterobacter, Klebsiella, Salmonella, have an additional global regulator, RamA. It plays a strategic role in controlling both the porins and the efflux expression, either directly or via the MarA cascade. This coordinated control of influx and efflux directly and efficiently governs the intracellular accumulation of antibacterial agents. Importantly, this internal accumulation of antibacterial molecules below the threshold corresponding to the MIC can favor the emergence and acquisition of additional mechanisms of resistance such as target mutation, production of detoxifying enzymes (e.g., $\beta$-lactamases, acetyltransferase, etc), and contributing to the extension of MDR phenotype (Nikaido and Pagès, 2012; Masi and Pagès, 2013).

Regarding the active structure of efflux pumps involved in E. aerogenes and E. cloacae; we can hypothesize that a common structural organization is conserved, due to the high conserved homology between Enterobacter and E. coli. This structural organization can be similar to the recent description of the AcrAB-TolC complex in E. coli (Du et al., 2014).

\section{Mutations and Antibiotic Resistance}

Regarding the $\beta$-lactam antibiotics, the resistance due to target mutation occurs incidentally in Enterobacter sp. However, the diverse $\beta$-lactamases identified today is the result of a series of mutations that have successively appeared in the original $\beta$-lactamases TEM-1/2, SHV-1, OXA-1.

Furthermore, strains in which AmpC cephalosporinase was derepressed have been affected by mutations affecting AmpRpromoter recognition site. Mutations that are best known and studied are those that affect the target of fluoroquinolones and more recently those responsible for polymyxin resistance. As a matter of fact, the quinolones were widely prescribed antimicrobial agents because of their proven safety, high oral bioavailability, multiple approved indications, and bactericidal 
activity. Consequently, in the microbial population, a variety of amino acid alterations arose from mutations within quinolone resistance-determining regions (QRDRs) of cellular target genes gyrA and parC and conferred high-level resistance. This is one of the most common resistance mechanisms identified among clinical isolates of Enterobacter, despite recent characterization of plasmid-mediated quinolone resistance (PMQR) genes ( $q n r A, q n r S, a a c\left(6^{\prime}\right)-I b-c r, q e p A$, and oqxAB; Park et al., 2009; Kanamori et al., 2012). In E. cloacae the plasmid-borne QnrA and QnrS resistances inducing protection from the DNA binding of fluoroquinolones are observed, but such mechanisms confers low-level resistance when present alone (Corkill et al., 2005; Poirel et al., 2005; Huang et al., 2012; Kanamori et al., 2012). However, such PMRQ mechanisms have got an efficient dissemination and are found in over $60 \%$ of the strains, because were found to be co-carried with various ESBLs or AmpC-type $\beta$-lactamases on the same plasmid (Park et al., 2009; Huang et al., 2012). Finally, associated to active efflux, target mutations are the most efficient resistance mechanisms resulting in high MICs values, while PMRQ mechanisms confer only an additive effect on the level of fluoroquinolones resistance.

Finally, pan-drug resistance is not an exceptional phenotype in $E$. aerogenes, since resistant strains to all antibiotics, including colistin pmrA substitution, were isolated and described to be associated with colistin resistance (Thiolas et al., 2005; Diene et al., 2013).

Regarding the permeation pathway, it is important to mention that during the last decade, we observed the emergence of well-located mutation inside the pore constriction of the Omp36 (OmpC like porin of E. aerogenes) that generate a strong resistance against $\beta$-lactams (Dé et al., 2001; Thiolas et al., 2004). This specific mutation altering the pore characteristics impairs the diffusion of all $\beta$-lactams including cephalosporins and carbapenems, represents the first type of an adaptative mutation of bacterial porin in a resistant clinical isolates of Enterobacteriaceae (Chevalier et al., 1999; Thiolas et al., 2004). Interestingly, the intensity of MIC modification conferred by the specific residues depends on the structure and charge of the antibiotic molecules. A recent study reports the molecular simulations and dynamics of $\beta$-lactams inside the wild type and mutated channel during the travel of the molecule from outside to the periplasmic space (Vidal et al., 2005; James et al., 2009; Hajjar et al., 2010a,b). These data illustrates the adaptive pressure that has governed the selection and the preservation of these specific residues that filter the diffusion of charged solutes. The amino acids involved represent the first defense against the penetration of harmful compounds and support the pioneer investigations reporting the difference in $\beta$-lactam susceptibility depending on porin (Pagès et al., 2008).

Recently, in the context of IMI-Translocation consortium (www.translocation.eu), the genomes of various clinical isolates have been sequenced and the preliminary analyses have reported several mutations in resistant strains that are located in the regulators and membrane proteins (data not shown).

\section{Regulation of Membrane-Associated Mechanisms of Resistance}

Various studies on antibiotic resistance in E. aerogenes and E. cloacae have enlightened on a group of AraC family regulators including MarA, RamA, SoxS, and RobA, which are associated with a phenotype of low-level susceptibility to several antibiotics and biocides by inducing the overexpression of the efflux pump (for a review see Davin-Regli et al., 2008; Davin-Regli and Pagès, 2012; Pérez et al., 2012). Interestingly, the role of marA and $\operatorname{ram} A$ has been described also in the downregulation of porins and the subsequent resistance to $\beta$-lactams in E. aerogenes that completes the MDR phenotype of clinical resistant strains (Chollet et al., 2002, 2004). Recent work has shown that the expression of another AraC- regulator, $\operatorname{rar} A$, contribute to a multidrug-resistance phenotype, generated via the activation of efflux (Veleba et al., 2013). This regulator also has a role in the development of tigecycline resistance (Veleba et al., 2013). Thus, the regulation of MDR in Enterobacter is quite complex and redundant (Davin-Regli et al., 2008; Lawler et al., 2013) and contributes to the rapid adaptation of the clinical isolate via the porin and efflux balance (Bornet et al., 2000, 2004). Moreover, it has been demonstrated that some two component system (TCS) regulators such as OmpR-EnvZ also play a key role in the control of porin expression in addition to OmpX and the small RNAi or proteins as H-NS that govern the OmpF/OmpC balance in E. coli or efflux pump elements synthesis in E. aerogenes, respectively (Stoorvogel et al., 1991; Masi et al., 2005; Dupont et al., 2007).

Interestingly, regarding the genetic control of the pump expression; activators MarA, RamA, and RarA, and repressors

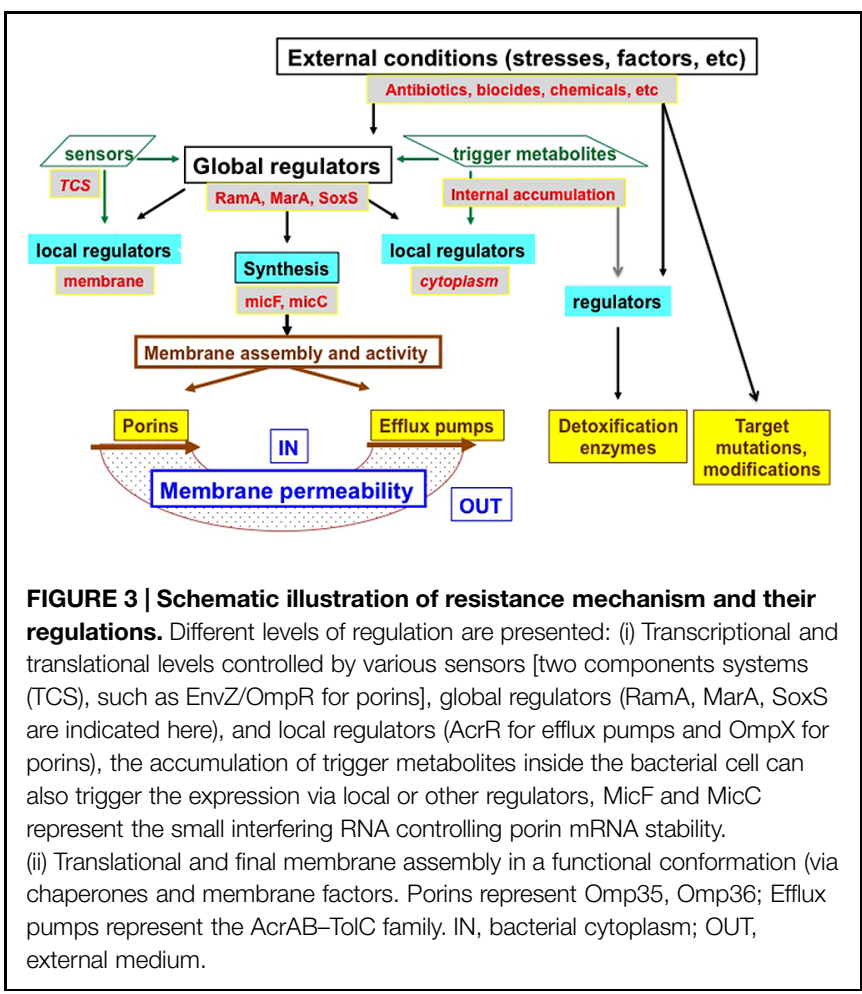


MarR, RamR, and AcrR, could be intimately associated at a global and local level to conjointly organize the resistance in clinical Enterobacter isolates (Davin-Regli et al., 2008). At this moment, it is also important to mention that the RamA regulator is described in Enterobacter, Salmonella, and Klebsiella, but not reported in Escherichia in contrast to the Mar regulon (Lawler et al., 2013).

An illustration of the sophisticated regulation of the various resistance mechanisms in Enterobacter is presented in Figure 3.

\section{Conclusion}

During the last decade, we observed the rise and the fall of several infectious episodes due to resistant Escherichia, Enterobacter, Klebsiella strains in French and European hospitals. Regarding Enterobacter, we can note the successive waves of E. cloacae, followed by E. aerogenes and now again E. cloacae reported in hospital wards (Potron et al., 2013). This bacterial species is a member of the ESKAPE group recently described as the main contributor to the health human infection problem (Boucher et al., 2009; Rice, 2010). Consequently, it is important to examine the various ways used by E. aerogenes and E. cloacae to detect and respond to the modification of environmental conditions and the presence of drugs in the medium.

Interestingly, the two Enterobacter species, aerogenes and cloacae, present highly preserved regulation mechanisms acting to modulate the expression of porins integrated into the outer membrane: for example OmpX the small outer membrane protein, plays a role in controlling the production of the OmpF-like porin (Omp35) and OmpX overproduction is reported in clinical isolates showing a porin failure (Stoorvogel et al., 1991; Dupont

\section{References}

Alekshun, M. N., and Levy, S. B. (2007). Molecular mechanisms of antibacterial multidrug resistance. Cell 128, 1037-1050. doi: 10.1016/j.cell.2007.03.004

Allerberger, F., Koeuth, T., Lass-Florl, C., Dierich, M. P., Putensen, C., Schmutzhard, E., et al. (1996). Epidemiology of infections due to multiresistant Enterobacter aerogenes in an university hospital. Eur. J. Clin. Microbiol. Infect. Dis. 15, 517-521. doi: 10.1007/BF01691323

Anastay, M., Lagier, E., Blanc, V., and Chardon, H. (2013). Epidémiologie des bêtalactamases à spectre étendu (BLSE) chez les entérobactéries dans un hôpital du sud de la France, 1997-2007. Pathol. Biol. 61, 38-43. doi: 10.1016/j.patbio.2012.03.001

Arpin, C., Coze, C., Rogues, A. M., Gachie, J. P., Bebear, C., and Quentin, C. (1996). Epidemiological study of an outbreak due to multidrug-resistant Enterobacter aerogenes in a medical intensive care unit. J. Clin. Microbiol. 34, 2163-2169.

Arpin, C., Labia, R., Dubois, V., Noury, P., Souquet, M., and Quentin, C. (2002). TEM-80, a novel inhibitor-resistant $\beta$-lactamase in a clinical isolate of Enterobacter cloacae. Antimicrob. Agents Chemother. 46, 1183-1189. doi: 10.1128/AAC.46.5.1183-1189.2002

Bertrand, X., Hocquet, D., Boisson, K., Siebor, E., Plésiat, P., and Talon, D. (2003). Molecular epidemiology of Enterobacteriaceae producing extended-spectrum $\beta$-lactamase in a French university-affiliated hospital. Int. J. Antimicrob. Agents 22, 128-133. doi: 10.1016/S0924-8579(03)00098-0

Biendo, M., Canarelli, B., Thomas, D., Rousseau, F., Hamdad, F., Adjide, C., et al. (2008). Successive emergence of extended-spectrum- $\beta$-lactamaseproducing and carbapenemase-producing Enterobacter aerogenes isolates in a university hospital. J. Clin. Microbiol. 46, 1037-1044. doi: 10.1128/JCM. 00197-07 et al., 2007). This control of an outer membrane protein (OmpX) on the synthesis of the outer membrane porin, in addition to the major regulator of the resistance cascade that are fully active, are present in various clinical isolates. This suggests a common evolution path and the selection of a common regulation cascade involved in the membrane adaptation to environmental stresses (Gayet et al., 2003). About the drug transporters, it is clear that AcrAB-TolC system, OqxAB, EmrE, MdfA, and MacA are present in the two species (see data bank for a complete description). In addition, regarding Mar, Ram, and Sox regulators all of them are preserved and active in the triggering of antibiotic resistance. Interestingly, the redundant global regulatory control, Mar and Ram, are reported in E. aerogenes and E. cloacae (Veleba et al., 2013). The close species proximity is reinforced by the presence of similar regulators and adaptive response and support the description of these species in the human infection and their response face to antibiotic therapy.

\section{Acknowledgments}

We greatly appreciate the S. Dam s' help for his carefully reading of the manuscript. This work was supported by Aix-Marseille Université. The research leading to the results discussed here was conduced as part of the translocation consortium (www.translocation.eu) and has received support from the Innovative Medicines joint Undertaking under Grant Agreement no. 115525, resources which are composed of financial contribution from the European Union's seventh framework program (FP/2007-2013) and EFPIA companies in kind contributions.

Bornet, C., Davin-Regli, A., Bosi, C., Pagès, J. M., and Bollet, C. (2000). Imipenem resistance of Enterobacter aerogenes mediated by outer membrane permeability. J. Clin. Microbiol. 38, 1048-1052.

Bornet, C., Saint, N., Fetnaci, L., Dupont, M., Davin-Régli, A., Bollet, C., et al. (2004). Omp35, a new Enterobacter aerogenes porin involved in selective susceptibility to cephalosporins. Antimicrob. Agents Chemother. 48, 2153-2158. doi: 10.1128/AAC.48.6.2153-2158.2004

Bosi, C., Davin-Regli, A., Bornet, C., Malléa, M., Pagès, J. M., and Bollet, C. (1999). Most Enterobacter aerogenes strains in France belong to a prevalent clone. J. Clin. Microbiol. 37, 2165-2169.

Boucher, H. W., Talbot, G. H., Bradley, J. S., Edwards, J. E., Gilbert, D., Rice, L. B., et al. (2009). Bad bugs, no drugs: no ESKAPE! an update from the Infectious Diseases Society of America. Clin. Infect. Dis. 48, 1-12. doi: 10.1086/595011

Carbonne, A., Arnaud, I., Maugat, S., Marty, N., Dumartin, C., Bertrand, X., et al. (2013). National multidrug-resistant bacteria (MDRB) surveillance in France through the RAISIN network: a 9 year experience. J. Antimicrob. Chemother. 68, 954-959. doi: 10.1093/jac/dks464

Charrel, R. N., Pagès, J. M., De Micco, P., and Malléa, M. (1996). Prevalence of outer membrane porin alteration in $\beta$-lactam-antibiotic-resistant Enterobacter aerogenes. Antimicrob. Agents Chemother. 40, 2854-2858.

Chevalier, J., Malléa, M., and Pagès, J. M. (2000). Comparative aspects of the diffusion of norfloxacin, cefepime and spermine through the $\mathrm{F}$ porin channel of Enterobacter cloacae. Biochem. J. 348(Pt 1), 223-227. doi: 10.1042/02646021:3480223

Chevalier, J., Mulfinger, C., Garnotel, E., Nicolas, P., Davin-Régli, A., and Pagès, J. M. (2008). Identification and evolution of drug efflux pump in clinical Enterobacter aerogenes strains isolated in 1995 and 2003. PLoS ONE 3:e3203. doi: 10.1371/journal.pone.0003203 
Chevalier, J., Pagès, J. M., and Malléa, M. (1999). In vivo modification of porin activity conferring antibiotic resistance to Enterobacter aerogenes. Biochem. Biophys. Res. Commun. 266, 248-251. doi: 10.1006/bbrc.1999.1795

Chollet, R., Bollet, C., Chevalier, J., Malléa, M., Pagès, J. M., and Davin-Regli, A. (2002). mar operon involved in multidrug resistance of Enterobacter aerogenes. Antimicrob. Agents Chemother. 46, 1093-1097. doi: 10.1128/AAC.46.4.10931097.2002

Chollet, R., Chevalier, J., Bollet, C., Pagès, J. M., and Davin-Regli, A. (2004). RamA is an alternate activator of the multidrug resistance cascade in Enterobacter aerogenes. Antimicrob. Agents Chemother. 48, 2518-2523. doi: 10.1128/AAC.48.7.2518-2523.2004

Corkill, J. E., Anson, J. J., and Hart, C. A. (2005). High prevalence of the plasmidmediated quinolone resistance determinant qnrA in multidrug-resistant Enterobacteriaceae from the blood cultures in Liverpool, UK. J. Antimicrob. Chemother. 56, 1115-1117. doi: 10.1093/jac/dki388

Dai, W., Sun, S., Yang, P., Huang, S., Zhang, X., and Zhang, L. (2013). Characterization of carbapenemases, extended spectrum $\beta$-lactamases and molecular epidemiology of carbapenem-non-susceptible Enterobacter cloacae in a Chinese hospital in ChongqinG. Infect. Genet. Evol. 14, 1-7. doi: 10.1016/j.meegid.2012.10.010

Davin-Regli, A., Bolla, J. M., James, C. E., Lavigne, J. P., Chevalier, J., Garnotel, E., et al. (2008). Membrane permeability and regulation of drug "influx and efflux" in enterobacterial pathogens. Curr. Drug Targets 9, 750-759. doi: $10.2174 / 138945008785747824$

Davin-Regli, A., Monnet, D., Saux, P., Bosi, C., Charrel, R. N., Barthelemy, A., et al. (1996). Molecular epidemiology of Enterobacter aerogenes acquisition: oneyear prospective study in two intensive care units. J. Clin. Microbiol. 34, 14741480.

Davin-Regli, A., and Pagès, J. M. (2012). Cross-resistance between biocides and antimicrobials: an emerging question. Rev. Sci. Tech. 31, 89-104.

Dé, E., Baslé, A., Jaquinod, M., Saint, N., Malléa, M., Molle, G., et al. (2001). A new mechanism of antibiotic resistance in Enterobacteriaceae induced by a structural modification of the major porin. Mol. Microbiol. 41, 189-198. doi: 10.1046/j.1365-2958.2001.02501.x

De Champs, C., Sauvant, M. P., Chanal, C., Sirot, D., Gazuy, N., Malhuret, R., et al. (1989). Prospective survey of colonization and infection caused by expanded spectrum-beta-lactamase-producing members of the family Enterobacteriaceae in an intensive care unit. J. Antimicrob. Chemother. 27, 2887-2890.

De Gheldre, Y., Maes, N., Rost, F., De Ryck, R., Clevenbergh, P., Vincent, J. L., et al. (1997). Molecular epidemiology of an outbreak of multidrug-resistant Enterobacter aerogenes infections and in vivo emergence of imipenem resistance. J. Clin. Microbiol. 35, 152-160.

Diene, S. M., Merhej, V., Henry, M., El Filali, A., Roux, V., Robert, C., et al. (2013). The rhizome of the multidrug-resistant Enterobacter aerogenes genome reveals how new "killer bugs" are created because of a sympatric lifestyle. Mol. Biol. Evol. 30, 369-383. doi: 10.1093/molbev/mss236

Doumith, M., Ellington, M. J., Livermore, D. M., and Woodford, N. (2009). Molecular mechanisms disrupting porin expression in ertapenem-resistant Klebsiella and Enterobacter spp. clinical isolates from the UK. J. Antimicrob. Chemother. 63, 659-667. doi: 10.1093/jac/dkp029

Du, D., Wang, Z., James, N. R., Voss, J. E., Klimont, E., Ohene-Agyei, T., et al. (2014). Structure of the AcrAB-TolC multidrug efflux pump. Nature 509, 512-515. doi: 10.1038/nature13205

Dugleux, G., Le Coutour, X., Hecquard, C., and Oblin, I. (1991). Septicemia caused by contaminated parenteral nutrition pouches: the refrigerator as an unual cause. J. Parent. Ent. Nutr. 15, 474-475. doi: 10.1177/0148607191015004474

Dumarche, P., De Champs, C., Sirot, D., Chanal, C., Bonnet, R., and Sirot, J. (2002). TEM derivative-producing Enterobacter aerogenes strains: dissemination of a prevalent clone. Antimicrob. Agents Chemother. 46, 1128-1131. doi: 10.1128/AAC.46.4.1128-1131.2002

Dupont, M., James, C. E., Chevalier, J., and Pagès, J. M. (2007). An early response to environmental stress involves regulation of OmpX and OmpF, two enterobacterial outer membrane pore-forming proteins. Antimicrob. Agents Chemother. 51, 3190-3198. doi: 10.1128/AAC.01481-06

Farmer, J. J. III, Davis, B. R., Hickman-Brenner, F. W., McWorther, A., HuntleyCarter, G. P., Asbury, M. A., et al. (1985). Biochemical identification of new species and biogroups of Enterobacteriaceae isolated from clinical specimens. J. Clin. Microbiol. 21, 46-76.
Fata, F., Chittivelu, S., Tessler, S., and Kupper, Y. (1996). Gas gangrene of the arm due to Enterobacter cloacae in a neutropenic patient. South. Med. J. 89, 1095-1096. doi: 10.1097/00007611-199611000-00014

Fernandez-Baca, V., Ballesteros, F., Hervas, J. A.,Villalon, P., and Alberti, S. (2001). Molecular epidemiological typing of Enterobacter cloacae isolates from a neonatal intensive care unit: three-year prospective study. J. Hosp. Infect. 49, 173-182. doi: 10.1053/jhin.2001.1053

Fernandez-Cuenca, F., Rodriguez-Martinez, J. M., Martinez-Martinez, J. M. and Pascual, J. M. (2006). In vivo selection of Enterobacter aerogenes with reduced susceptibility to cefepime and carbapenems associated with decreased expression of a $40 \mathrm{kDa}$ outer membrane protein and hyperproduction of AmpC $\beta$-lactamase. Int. J. Antimicrob. Agents 27, 549-552. doi: 10.1016/j.ijantimicag.2006.01.005

Freney, J., Husson, M. O., Gavini, F., Madier, S., Martra, A., Izard, D., et al. (1988). Susceptibility to antibiotics and antiseptics of new species of the family Enterobacteriaceae. Antimicrob. Agents Chemother. 32, 873-876. doi: 10.1128/AAC.32.6.873

Galani, I., Souli, M., Chryssouli, Z., Orlandou, K., and Giamarellou, H. (2005). Characterization of a new integron containing, bla (VIM-1) and aac(6')-IIc in an Enterobacter cloacae clinical isolate from Greece. J. Antimicrob. Chemother. 55, 634-638. doi: 10.1093/jac/dki073

Galas, M., Decousser, J.-W., Breton, N., Godard, T., Allouch, T., Pina, P., et al. (2008). Nationwide study of the prevalence, characteristics, and molecular epidemiology of extended-spectrum- $\beta$-lactamase-producing Enterobacteriaceae in France. Antimicrob. Agents Chemother. 52, 786-789. doi: 10.1128/AAC.00906-07

Gayet, S., Chollet, R., Molle, G., Pagès, J. M., and Chevalier, J. (2003). Modification of outer membrane protein profile and evidence suggesting an active drug pump in Enterobacter aerogenes clinical strains. Antimicrob. Agents Chemother. 47, 1555-1559. doi: 10.1128/AAC.47.5.1555-1559.2003

Georghiou, P. R., Hamill, R. J., Wright, C. E., Versalovic, J., Koeuth, T. T., and Lupski, J. R. (1995). Molecular epidemiology of infections due to Enterobacter aerogenes: identification of hospital outbreak-associated strains by molecular techniques. Clin. Infect. Dis. 20, 84-94. doi: 10.1093/clinids/20.1.84

Grattard, F., Pozzetto, B., Tabard, L., Petit, M., Ros, A., and Gaudin, O. G. (1995). Characterization of nosocomial strains of Enterobacter aerogenes by arbitrarily primed PCR analysis and ribotyping. Infect. Control Hosp. Epidemiol. 16, 224-230. doi: 10.2307/30140982

Hajjar, E., Bessonov, A., Molitor, A., Kumar, A., Mahendran, K. R., Winterhalter, M., et al. (2010a). Toward screening for antibiotics with enhanced permeation properties through bacterial porins. Biochemistry 49, 6928-6935. doi: 10.1021/bi100845x

Hajjar, E., Mahendran, K. R., Kumar, A., Bessonov, A., Petrescu, M., Weingart, H., et al. (2010b). Bridging timescales and length scales: from macroscopic flux to the molecular mechanism of antibiotic diffusion through porins. Biophys. J. 98 569-575. doi: 10.1016/j.bpj.2009.10.045

Hammami, S., Boutiba-Ben Boubaker, I., Saidani, M, Lakhal, E., Ben Hassen, A., Kamoun, A., et al. (2012). Characterization and molecular epidemiology of extended spectrum beta-lactamase producing Enterobacter cloacae isolated from a Tunisian hospital. Microb. Drug Resist. 18, 59-65. doi: 10.1089/mdr.2011.0074

Hamprecht, A., Poirel, L., Gottig, S., Seifert, H., Kaase, M., and Nordmann P. (2013). Detection of the carbapenemase GIM-1 in Enterobacter cloacae in Germany. J. Antimicrob. Chemother. 68, 558-561. doi: 10.1093/jac/dks447

He, G. X., Thorpe, C., Walsh, D., Crow, R., Chen, H., Kumar, S., et al. (2011). EmmdR, a new member of the MATE family of multidrug transporters, extrudes quinolones from Enterobacter cloacae. Arch. Microbiol. 193, 759-765. doi: 10.1007/s00203-011-0738-1

Huang, S., Dai, W., Sun, S., Zhang, X., and Zhang, L. (2012). Prevalence of plasmid-mediated quinolone resistance and aminoglycoside resistance determinants among carbapeneme non-susceptible Enterobacter cloacae. PLoS ONE 7:e47636. doi: 10.1371/journal.pone.0047636

Izdebski, R., Baraniak, A., Herda, M., Fiett, J., Bonten, M. J., Carmeli, Y., et al. (2014). MLST reveals potentially high-risk international clones of Enterobacter cloacae. J. Antimicrob. Chemother. 70, 48-56. doi: 10.1093/jac/dku359

Jalaluddin, S., Devaster, J. M., Scheen, R., Gerard, M., and Butzler, J. P. (1998). Molecular epidemiological study of nosocomial Enterobacter aerogenes isolates in a Belgian hospital. J. Clin. Microbiol. 36, 1846-1852. 
James, C. E., Mahendran, K. R., Molitor, A., Bolla, J. M., Bessonov, A. N., Winterhalter, M., et al. (2009). How beta-lactam antibiotics enter bacteria: a dialogue with the porins. PLoS ONE 4:e5453. doi: 10.1371/journal.pone.0005453

Jarlier, V., and INVS. (2014). Surveillance of Multidrug Resistant Bacteria in French Healthcare Facilities BMR-Raisin Network Données 2012. Saint-Maurice: Institut de Veille Sanitaire. Available at: http://www.invs.sante.fr

Jaskulski, M. R., Medeiros, B. C., Borges, J. V., Zalewsky, R., Fonseca, M. E., Marinowic, D. R., et al. (2013). Assessment of extended-spectrum $\beta$-lactamase, KPC carbapenemase and porin resistance mechanisms in clinical samples of Klebsiella pneumoniae and Enterobacter spp. Int. J. Antimicrob. Agents 42, 76-79. doi: 10.1016/j.ijantimicag.2013.03.009

Kanamori, H., Hisakasu, Y., Yoichi, H., H Ayako, H., Kazuaki, A., Kunishima, H., et al. (2012). Molecular characteristics of extended-spectrum $\beta$-lactamases and qnr determinants in Enterobacter species from Japan. PLoS ONE 7:e37967. doi: 10.1371/journal.pone.0037967

Khajuria, A., Praharaj, A. K., Kumar, M., and Grover, N. (2014). Carbapenem resistance among Enterobacter species in a tertiary care hospital in central India. Chemother. Res. Pract. 2014:972646. doi: 10.1155/2014/972646

Kim, S. Y., Park, Y. J., Yu, J. K., Kim, Y. S., and Han, K. (2009). Prevalence and characteristics of $\mathrm{aac}\left(6^{\prime}\right)-\mathrm{Ib}-\mathrm{cr}$ in AmpC-producing Enterobacter cloacae, Citrobacter freundii, and Serratia marcescens: a multicenter study from Korea. Diagn. Microbiol. Infect. Dis. 63, 314-318. doi: 10.1016/j.diagmicrobio.2008.11.016

Langley, J. M., Hanakowski, M., and Leblanc, J. C. (2001). Unique epidemiology of nosocomial urinary tract infection in children. Am. J. Infect. Control 29, 94-98. doi: $10.1067 /$ mic. 2001.111537

Lavigne, J. P., Sotto, A., Nicolas-Chanoine, M. H., Bouziges, N., Bourg, G., Davin-Regli, A., et al. (2012). Membrane permeability, a pivotal function involved in antibiotic resistance and virulence in Enterobacter aerogenes clinical isolates. Clin. Microbiol. Infect. 18, 539-545. doi: 10.1111/j.1469-0691.2011. 03607.x

Lavigne, J. P., Sotto, A., Nicolas-Chanoine, M. H., Bouziges, N., Pagès, J. M., and Davin-Regli, A. (2013). An adaptive response of Enterobacter aerogenes to imipenem: regulation of porin balance in clinical isolates. Int. J. Antimicrob. Agents 41, 130-136. doi: 10.1016/j.ijantimicag.2012.10.010

Lawler, A. J., Ricci, V., Busby, S. J., and Piddock, L. J. (2013). Genetic inactivation of acrAB or inhibition of efflux induces expression of ramA. J. Antimicrob. Chemother. 68, 1551-1557. doi: 10.1093/jac/dkt069

Lee, E. H., Collatz, E., Trias, J., and Gutmann, L. (1992). Diffusion of $\beta$-lactam antibiotics into proteoliposomes reconstituted with outer membranes of isogenic imipenem-susceptible and -resistant strains of Enterobacter cloacae. J. Gen. Microbiol. 138, 2347-2351. doi: 10.1099/00221287-138-11-2347

Lee, H. K., Park, Y. J., Kim, J. Y., Chang, E., Cho, S. G., Chae, H. S., et al. (2005). Prevalence of decreased susceptibility to carbapenems among Serratia marcescens, Enterobacter cloacae, and Citrobacter freundii and investigation of carbapenemases. Diagn. Microbiol. Infect. Dis. 52, 331-336. doi: 10.1016/j.diagmicrobio.2005.04.012

Lee, S. H., Jeong, S. H., and Park, Y. M. (2003). Characterization of blaCMY-10 a novel, plasmid-encoded AmpC -type $\beta$-lactamase gene in a clinical isolate of Enterobacter aerogenes. J. Appl. Microbiol. 95, 744-752. doi: 10.1046/j.13652672.2003.02040.x

Levy, S. B. (2002). Active efflux, a common mechanism for biocide and antibiotic resistance. Symp. Ser. Soc. Appl. Microbiol. 92, 65S-71S. doi: 10.1046/j.13652672.92.5s1.4.x

Malléa, M., Chevalier, J., Bornet, C. E., Eyraud, A., Davin-Regli, A., Bollet, C., et al. (1998). Porin alteration and active efflux: two in vivo drug resistance strategies used by Enterobacter aerogenes. Microbiology 144, 3003-3009. doi: 10.1099/00221287-144-11-3003

Malléa, M., Simonet, V., Lee, E. H., Gervier, R., Collatz, E., Gutmann, L., et al. (1995). Biological and immunological comparisons of Enterobacter cloacae and Escherichia coli porins. FEMS Microbiol. Lett. 129, 273-279. doi: 10.1016/03781097(95)00171-Z

Martins, A., Spengler, G., Martins, M., Rodrigues, L., Viveiros, M., Davin-Regli, A., et al. (2010). Physiological characterisation of the efflux pump system of antibiotic-susceptible and multidrug-resistant Enterobacter aerogenes. Int. J. Antimicrob. Agents 36, 313-318. doi: 10.1016/j.ijantimicag.2010.06.036

Masi, M., and Pagès, J. M. (2013). Structure, function and regulation of outer membrane proteins involved in drug transport in
Enterobactericeae: the OmpF/C - TolC case. Open Microbiol. J. 7, 22-33. doi: 10.2174/1874285801307010022

Masi, M., Pagès, J. M., and Pradel, E. (2006). Production of the cryptic EefABC efflux pump in Enterobacter aerogenes chloramphenicol-resistant mutants. J. Antimicrob. Chemother. 57, 1223-1226. doi: 10.1093/jac/dkl139

Masi, M., Pagès, J. M., Villard, C., and Pradel, E. (2005). The eefABC multidrug efflux pump operon is repressed by H-NS in Enterobacter aerogenes. J. Bacteriol. 187, 3894-3897. doi: 10.1128/JB.187.11.3894-3897.2005

Mezzatesta, M. L., Gona, F., and Stefani, S. (2012). Enterobacter cloacae complex: clinical impact and emerging antibiotic resistance. Future Microbiol. 7, 887-902. doi: $10.2217 / \mathrm{fmb} .12 .61$

Miro, E., Alonso, C., Navarro, F., Mirelis, B., and Prats, G. (1995). Resistencia al imipenem en Enterobacter aerogenes. Enferm. Infecc. Microbiol. Clin. 13, 278-282.

Miró, E., Grünbaum, F., Gómez, L., Rivera, A., Mirelis, B., Coll, P., et al. (2013). Characterization of aminoglycoside-modifying enzymes in Enterobacteriaceae clinical strains and characterization of the plasmids implicated in their diffusion. Microb. Drug Resist. 19, 94-99. doi: 10.1089/mdr.2012.0125

Nauciel, C., Philippon, A., Ronco, E., Pilliot, J., Guenounou, M., Paul, G., et al. (1985). Septicémies à Enterobacter cloacae et E. aerogenes: émergence de variants résistants. Presse Med. 14, 673-676.

Neuwirth, C., Siebor, E., Lopez, J., Pechinot, A., and Kazmierczak, A. (1996). Outbreak of TEM-24-producing Enterobacter aerogenes in an intensive care unit and dissemination of the extended-spectrum $\beta$-lactamase to other members of the family Enterobacteriacae. J. Clin. Microbiol. 34, 76-79.

Nikaido, H., and Pagès, J. M. (2012). Broad-specificity efflux pumps and their role in multidrug resistance of Gram-negative bacteria. FEMS Microbiol. Rev. 36, 340-363. doi: 10.1111/j.1574-6976.2011.00290.x

Nordmann, P., Mariotte, S., Naas, T., Labia, R., and Nicolas, M. H. (1993). Biochemical properties of a carbapenem-hydrolyzing beta-lactamase from Enterobacter cloacae and cloning of the gene into Escherichia coli. Antimicrob. Agents Chemother. 37, 939-946. doi: 10.1128/AAC.37.5.939

Pagès, J. M., James, C. E., and Winterhalter, M. (2008). The porin and the permeating antibiotic: a selective diffusion barrier in Gram-negative bacteria. Nat. Rev. Microbiol. 6, 893-903. doi: 10.1038/nrmicro1994

Park, Y.-J., Yu, J.-K., Kim, S.-I., Lee, K., and Arakawa, Y. (2009). Accumulation of plasmid-mediated fluoroquinolone resistance genes, qepA and qnrS1, in Enterobacter aerogenes co-producing RmtB and Class A $\beta$-lactamase LAP-1. Ann. Clin. Lab. Sci. 39, 55-59.

Pérez, A., Canle, D., Latasa, C., Poza, M., Beceiro, A., Tomás Mdel, M., et al. (2007). Cloning, nucleotide sequencing, and analysis of the AcrAB-TolC efflux pump of Enterobacter cloacae and determination of its involvement in antibiotic resistance in a clinical isolate. Antimicrob. Agents Chemother. 51, 3247-3253. doi: 10.1128/AAC.00072-07

Pérez, A., Poza, M., Aranda, J., Latasa, C., Medrano, F. J., Tomás, M., et al. (2012). Effect of transcriptional activators SoxS, RobA, and RamA on expression of multidrug efflux pump AcrAB-TolC in Enterobacter cloacae. Antimicrob. Agents Chemother. 56, 6256-6266. doi: 10.1128/AAC.01085-12

Pestourie, N., Garnier, F., Barraud, O., Bedu, A., Ploy, M. C., and Mounier, M. (2014). Outbreak of AmpC $\beta$-lactamase-hyper-producing Enterobacter cloacae in a neonatal intensive care unit in a French teaching hospital. Am. J. Infect. Control 42, 456-458. doi: 10.1016/j.ajic.2013.11.005

Piddock, L. J. (2006). Clinically relevant chromosomally encoded multidrug resistance efflux pumps in bacteria. Clin. Microbiol. Rev. 19, 382-402. doi: 10.1128/CMR.19.2.382-402.2006

Pitout, J. D., Sanders, C. C., and Sanders, W. E. Jr. (1997). Antimicrobial resistance with focus on beta-lactam resistance in gram-negative bacilli. Am. J. Med. 103, 51-59. doi: 10.1016/S0002-9343(97)00044-2

Pitout, J. D. D., Thomson, K. S., Hanson, N. D., Ehrhardt, A. F., Coudron, P., and Sanders, C. C. (1998). Plasmid-mediated resistance to expanded-spectrum cephalosporins among Enterobacter aerogenes strains. Antimicrob. Agents Chemother. 42, 596-600.

Poirel, L., Pitout, J. D., and Nordmann, P. (2007). Carbapenemases: molecular diversity and clinical consequences. Future Microbiol. 2, 501-512. doi: 10.2217/17460913.2.5.501

Poirel, L., Van De Loo, M., Mammeri, H., and Nordmann, P. (2005). Association of plasmid-mediated quinolone resistance with extended-spectrum 
beta-lactamase VEB-1. Antimicrob. Agents Chemother. 49, 3091-3094. doi: 10.1128/AAC.49.7.3091-3094.2005

Potron, A., Poirel, L., Rondinaud, E., and Nordmann, P. (2013). Intercontinental spread of OXA-48 $\beta$-lactamase-producing Enterobacteriaceae over a 11year period, 2001 to 2011. Euro. Surveill. 18:20549. doi: 10.2807/15607917.ES2013.18.31.20549

Pradel, E., and Pagès, J. M. (2002). The AcrAB-TolC efflux pump contributes to multidrug resistance in the nosocomial pathogen Enterobacter aerogenes. Antimicrob. Agents Chemother. 46, 2640-2643. doi: 10.1128/AAC.46.8.26402643.2002

Preston, K. E., Radomski, C. C. A., and Venezia, R. A. (2000). Nucleotide sequence of the chromosomal ampC gene of Enterobacter aerogenes. Antimicrob. Agents Chemother. 44, 3158-3162. doi: 10.1128/AAC.44.11.3158-3162.2000

Quiroga, M. P., Andres, P., Petroni, A., Soler Bistué, A. J., Guerriero, L., Vargas, L. J., et al. (2007). Complex class 1 integrons with diverse variable regions, including aac (6')-Ib-cr, and a novel allele, qnrB10, associated with ISCR1 in clinical enterobacterial isolates from Argentina. Antimicrob. Agents Chemother. 51, 4466-4470. doi: 10.1128/AAC.00726-07

Raimondi, A., Traverso, A., and Nikaido, H. (1991). Imipenem- and meropenemresistant mutants of Enterobacter cloacae and Proteus rettgeri lack porins. Antimicrob. Agents Chemother. 35, 1174-1180. doi: 10.1128/AAC.35.6.1174

Rice, L. B. (2010). Progress, and challenges in implementing the research on ESKAPE pathogens. Infect. Control. Hosp. Epidemiol. Suppl. 1, S7-S10. doi: $10.1086 / 655995$

Robert, J., Pantel, A., Mérens, A., Lavigne, J. P., Nicolas-Chanoine, M. H., and ONERBA's Carbapenem Resistance Study Group. (2014). Incidence rates of carbapenemase-producing Enterobacteriaceae clinical isolates in France: a prospective nationwide study in 2011-12. J. Antimicrob. Chemother. 69, 27062712. doi: $10.1093 / \mathrm{jac} / \mathrm{dku} 208$

Sanders, W. E., and Sanders, C. C. (1997). Enterobacter spp.: pathogens poised to flourish at the turn of the century. Clin. Microbiol. Rev. 10, 220-241.

Song, E.-H., Park, K.-H., Jang, E.-Y., Lee, E.-J., Chong, Y.-P., Cho, O.-H., et al. (2010). Comparison of the clinical and microbiologic characteristics of patients with Enterobacter cloacae and Enterobacter aerogenes bacteremia: a prospective observation study. Diagnos. Microbiol. Infect. Dis. 66, 436-440. doi: 10.1016/j.diagmicrobio.2009.11.007

Stoorvogel, J., van Bussel, M. J., Tommassen, J., and van de Klundert, J. A. (1991). Molecular characterization of an Enterobacter cloacae outer membrane protein (OmpX). J. Bacteriol. 173, 156-160.

Szabo, D., Melan, M. A., Hujer, A. M., Bonomo, R. A. Hujer, K. M., Bethel, C. R., et al. (2005). Molecular analysis of the simultaneous production of two SHVtype extended-spectrum beta-lactamases in a clinical isolate of Enterobacter cloacae by using single-nucleotide polymorphism genotyping. Antimicrob. Agents Chemother. 49, 4716-4720. doi: 10.1128/AAC.49.11.4716-4720.2005

Thiolas, A., Bollet, C., La Scola, B., Raoult, D., and Pagès, J. M. (2005). Successive emergence of Enterobacter aerogenes strains resistant to imipenem and colistin in a patient. Antimicrob. Agents Chemother. 49, 1354-1358. doi: 10.1128/AAC.49.4.1354-1358.2005
Thiolas, A., Bornet, C., Davin-Regli, A., Pagès, J. M., and Bollet, C. (2004). Resistance to imipenem, cefepime, and cefpirome associated with mutation in Omp36 osmoporin of Enterobacter aerogenes. Biochem. Biophys. Res. Commun. 317, 851-856. doi: 10.1016/j.bbrc.2004.03.130

Torres, E., López-Cerero, L., Del Toro, M. D., and Pascual, A. (2014). First detection and characterization of an OXA-48-producing Enterobacter aerogenes isolate. Enferm. Infecc. Microbiol. Clin. 32, 469-470. doi: 10.1016/j.eimc.2013.10.008

Tran, Q. T., Dupont, M., Lavigne, J. P., Chevalier, J., Pagès, J. M., Sotto, A., et al. (2009). Occurrence of efflux mechanism and cephalosporinase variant in a population of Enterobacter aerogenes and Klebsiella pneumoniae isolates producing extended-spectrum beta-lactamases. Antimicrob. Agents Chemother. 53, 1652-1656. doi: 10.1128/AAC.00822-08

Valade, E., Davin-Regli, A., Bolla, J.-M., and Pagès, J.-M. (2013). "Bacterial membrane, a key for controlling drug influx and efflux," in Antibiotics: Targets, Mechanisms and Resistance, eds C. O. Gualerzi, L. Brandi, A. Fabbretti, and C. L. Pon (Weinheim: Wiley-VCH Verlag GmbH \& Co. KGaA), 217-240. doi: 10.1002/9783527659685.ch9

Veleba, M., De Majumdar, S., Hornsey, M., Woodford, N., and Schneiders, T. (2013). Genetic characterization of tigecycline resistance in clinical isolates of Enterobacter cloacae and Enterobacter aerogenes. J. Antimicrob. Chemother. 68, 1011-1018. doi: 10.1093/jac/dks530

Vidal, S., Bredin, J., Pagès, J.-M., and Barbe, J. (2005). $\beta$-lactam screening by specific residues of the OmpF eyelet. J. Med. Chem. 48, 1395-400. doi: $10.1021 / \mathrm{jm} 049652 \mathrm{e}$

Wang, S. A., Tokars, J. I., Bianchine, P. J., Carson, L. A., Arduino, M. J., Smith, A. L., et al. (2000). Enterobacter cloacae bloodstream infections traced to contamined human albumine. Clin. Infect. Dis. 30, 35-40. doi: 10.1086/313585

Yigit, H., Anderson, G. J., Biddle, J. W., Steward, C. D., Rasheed, J. K., Valera, L. L., et al. (2002). Carbapenem resistance in a clinical isolate of Enterobacter aerogenes is associated with decreased expression of $\mathrm{OmpF}$ and OmpC porin analogs. Antimicrob. Agents Chemother. 46, 3817-3822. doi: 10.1128/AAC.46.12.3817-3822.2002

Zaher, A., and Cimolai, N. (1997). ERIC-PCR typing profiles of Enterobacter cloacae are stable after development of advanced cephalosporin resistance. Int. J. Antimicrob. Agents 9, 165-167. doi: 10.1016/S0924-8579(97) 00046-0

Conflict of Interest Statement: The authors declare that the research was conducted in the absence of any commercial or financial relationships that could be construed as a potential conflict of interest.

Copyright $\odot 2015$ Davin-Regli and Pagès. This is an open-access article distributed under the terms of the Creative Commons Attribution License (CC BY). The use, distribution or reproduction in other forums is permitted, provided the original author(s) or licensor are credited and that the original publication in this journal is cited, in accordance with accepted academic practice. No use, distribution or reproduction is permitted which does not comply with these terms. 